\title{
School smoking policies and smoking prevalence among adolescents: multilevel analysis of cross-sectional data from Wales
}

\author{
Laurence Moore, Chris Roberts, Chris Tudor-Smith
}

\begin{abstract}
Objective-To examine the association between school smoking policies and smoking prevalence among pupils.

Design-Multilevel analysis of crosssectional data from surveys of schools and pupils.

Setting-55 secondary schools in Wales.

Subjects-55 teachers and 1375 pupils in year 11 (aged 15-16).

Main outcome measures-Self-reported smoking behaviour.

Results-The prevalence of daily smoking in schools with a written policy on smoking for pupils, teachers, and other adults, with no pupils or teachers allowed to smoke anywhere on the school premises, was $9.5 \% \quad(95 \%$ confidence interval (CI) $6.1 \%$ to $12.9 \%$ ). In schools with no policy on pupils' or teachers' smoking, $30.1 \%$ (95\% CI $23.6 \%$ to $36.6 \%$ ) of pupils reported daily smoking. In schools with an intermediate level of smoking policy, $21.0 \%$ (95\% CI $17.8 \%$ to $\mathbf{2 4 . 2 \% )}$ smoked every day. School smoking policy was associated with school level variation in daily smoking $(p=0.002)$. In multilevel analysis, after adjusting for pupils' sex, parents' and best friends' smoking status, parental expectations, and alienation from school, there was less unexplained school level variation, but school smoking policy remained significant $(p=0.041)$. The association of smoking policy with weekly smoking was weaker than for daily smoking, and not significant after adjustment for pupil level variables. Both daily and weekly smoking prevalence were lower in schools where pupils' smoking restrictions were always enforced. Enforcement of teacher smoking restrictions was not significantly associated with pupils' smoking.

Conclusions-This study demonstrates an association between policy strength, policy enforcement, and the prevalence of smoking among pupils, after having adjusted for pupil level characteristics. These findings suggest that the wider introduction of comprehensive school smoking policies may help reduce teenage smoking.

(Tobacco Control 2001;10:117-123)
\end{abstract}

Keywords: schools; smoking policy; smoking prevalence
Smoking prevalence among adolescents in Wales has risen steadily over the last decade. In $1990,14 \%$ of males and $22 \%$ of females aged 15-16 years reported smoking weekly, but by 1998 , these proportions had risen to $22 \%$ and $29 \%$, respectively. ${ }^{12}$ Action to reduce smoking among young people forms an important element of government public health policy. ${ }^{34}$

While the most popular approach to adolescent smoking prevention has been through school based educational programmes, evidence of effective practice is limited. Recent reviews come to similar conclusions: that adolescent smoking is influenced by a complex range of factors; smoking prevention is a difficult task; and no single approach is likely to be successful on its own. . $^{5-9}$

There has been a lack of research on the role that the school environment may have in influencing pupils' smoking behaviour, ${ }^{6-8} 10$ despite the increasing attention given to the health promoting school movement. ${ }^{11} 12$

An important aspect of the school environment that can be readily modified is that of the school's policy regarding smoking by pupils and others on the school premises. ${ }^{10}$ However, evidence to date on the effectiveness of such policies is mixed. An early study in California indicated that school smoking policy was associated with decreased amounts of smoking but not with smoking prevalence. ${ }^{13}$ More recently, studies in Belgium and the USA have demonstrated associations between policies and smoking prevalence, although the latter study emphasised that such associations were only seen when policies were strictly enforced. ${ }^{14}{ }^{15}$ Elsewhere, a study in Australia found minimal association between policy and smoking behaviour. ${ }^{16}$ However, these are the only published studies we have been able to identify, none of which have been conducted in the UK. This paper reports a multilevel analysis of cross-sectional data collected in Wales in 1998 , the main purpose of which was to identify the extent to which pupils' smoking behaviour was associated with their respective schools' no-smoking policy.

\section{Subjects and methods}

Data on the smoking behaviour of pupils in year 11 (aged 15-16 years) were obtained from the 1998 Welsh youth health survey. This survey forms part of the health behaviour in school aged children (HBSC) study, which is coordinated by the World Health Organisation and currently has representation from 29 countries across Europe and North America. 
The survey used a two stage cluster sampling procedure to recruit respondents. For the first stage, a stratified random sample of 80 secondary schools was selected from the lists of the 22 local education authorities (LEAs) in Wales, probability of selection being proportionate to school size to ensure pupils had an equal chance of selection. The sample included both state and independent schools; in 1998 there were 223 state schools and 26 independent schools in Wales. For the second stage, schools were asked to select randomly from the school registers approximately 30 pupils from year 11 . Where this proved administratively impossible, schools were permitted to choose unstreamed, mixed ability classes (for example, tutor groups) for inclusion in the survey. The use of specific subject classes (for example, science) or streamed classes was not permitted as these might not constitute a representative sample of pupils.

Data collection took place in the classroom under examination conditions. The questionnaire was administered by a trained interviewer to all sampled pupils attending school on the day of the survey; those pupils absent because of sickness or other reasons were not followed up. All the pupils were provided with individual unmarked envelopes in which to seal their questionnaires before returning them to the survey administrator. The pupil questionnaires included items on the smoking behaviour of the pupil, their friends and family, and questions on their relationships with peers and family, their school experiences, and their socioeconomic circumstances. The analysis of pupils' smoking behaviour presented in this paper is based on the responses to two questions. First, pupils were asked: "Have you EVER smoked tobacco, including cigarettes (even if it was only a puff or two)?” (responses: yes / no). Second, those responding positively to the first question were then asked: "How often do you smoke at present?" (responses: "every day"; "at least once a week but not every day"; "less than once a week"; "I do not smoke"). Full details of the survey design, sampling and data collection methods can be found elsewhere. ${ }^{117}$

At each school participating in the Welsh youth health survey, two copies of a questionnaire on the content and enforcement of smoking policies were left at the school when the pupil survey was conducted. The questionnaires were left for completion by the head teacher (or other member of the senior management team) and/or by the teacher with responsibility for health education. For schools where two questionnaires were completed, we have included in the analysis the responses from the most senior member of staff.

STATISTICAL ANALYSIS

Two binary variables were used to measure smoking behaviour; pupils were defined as a daily smoker if they had responded in the questionnaire that they had ever smoked and that they currently smoked cigarettes every day. Pupils defined as "weekly" smokers included all daily smokers, and also pupils who reported that they currently smoked at least once a week but not every day. A three level ordinal variable was used to represent the content of each school's no smoking policy. The levels were defined as: (1: strong) a written policy for pupils, teachers, and other adults with no pupils or teachers allowed to smoke anywhere on the school premises; (2: average) policies for pupils and teachers, but with at least one of these policies not written and/or teachers allowed to smoke in restricted areas; and (3: weak) either no smoking policy on pupils or no policy on teachers. Two further variables were specified, representing the enforcement of pupil and teacher restrictions respectively. These variables were calculated as sum scores of teachers' responses to questions on how often restrictions were enforced in different areas of the school. For each area where there was a restriction, the possible responses were: always; most of the time; sometimes; never. There were seven areas relating to pupil restrictions (for example, "in cloakrooms/ toilets", "in the playground/other outdoor area") for each of which the level of enforcement was coded $0-3$ to indicate increasing levels of enforcement. A sum score was then calculated (range 0-21, Cronbach's $\alpha$ 0.79 ) to indicate overall level of enforcement of pupil restrictions. Similarly, enforcement of restrictions was assessed in five areas relating to teachers (for example, "in the staff room", "outdoors on the school premises") and a sum score was derived (range 0-15, Cronbach's $\alpha$ $0.89)$.

Daily and weekly smoking prevalence were calculated within groups of schools defined by their policy content and by each of the two enforcement variables. Confidence intervals were estimated using Stata survey estimators, which took account of the clustering (non-independence) of pupils within schools. ${ }^{18}$ These estimators were also used in logistic regression analyses of daily and weekly smoking, in which a number of pupil level factors known to be associated with teenagers' smoking behaviour were included as potential predictor variables. These included the pupils' age and sex, the smoking status of their best friend, and six factors relating to parents, namely the smoking status of mother and father, school related parental support score, parental expectations of school performance, family structure, and ease of talking to parents about bothersome things. The definition of these parental factors is described in detail elsewhere, ${ }^{19}$ while another paper provides details of a further predictor variable, the alienation score, which is a composite variable reflecting pupils' enjoyment of school, their self perceived performance at school, and their intention to stay in full time education when they are aged $16 .^{20}$ Finally, a predictor variable representing socioeconomic status was included. The measure used was the family affluence score, which is a pupil relevant measure of family affluence that has been found to be associated with adolescents' health related behaviour. ${ }^{21}$ 
Those pupil level variables found to be significantly associated with smoking were then included as predictors in a series of multilevel logistic regression models, in which the school level policy variables were also included. The aim of the multilevel analysis was to identify how much variation in smoking prevalence there was between schools, and then to identify whether this interschool variation was caused by differences in the composition of schools, represented by the pupil level variables, or by school smoking policy. Multilevel models were estimated in MLwiN, ${ }^{22}$ using second order penalised quasi likelihood, ${ }^{23}$ and compared formally by a Wald test for added joint contrasts, and also by assessing the change in (unexplained) school level variance. All multivariable models were estimated twice: first, using a reduced dataset consisting of respondents providing data on all variables used in all models; and second, maximising the number of available respondents for each particular analysis, including the use of dummy variables for missing observations on categorical variables included in the regression.

\section{Results}

Of the 80 schools selected for the survey sample, 10 were independent schools. Sixty two schools agreed to participate, although five of these restricted the survey to pupils in years 7 and 9 (11-14 year olds); a further two schools did not return a teacher questionnaire. Table 1

Table 1 Extent of schools'smoking policy provision for pupils, teachers, and other adults at 55 schools completing pupil and teacher surveys

\begin{tabular}{lllll}
\hline & Written policy & Informal policy & No policy & Don't know \\
\hline Pupils & $39(71 \%)$ & $14(25 \%)$ & $1(2 \%)$ & $1(2 \%)$ \\
Teachers & $21(38 \%)$ & $26(47 \%)$ & $7(13 \%)$ & $1(2 \%)$ \\
Other adults & $17(31 \%)$ & $26(47 \%)$ & $8(15 \%)$ & $4(7 \%)$ \\
\hline
\end{tabular}

Table 2 Daily and weekly smoking prevalence (95\% confidence intervals) in groups defined by: (1) strength of school smoking policy; (2) enforcement of pupil smoking policy; and (3) enforcement of teacher smoking policy

\begin{tabular}{lll}
\hline & Daily smoking (\%) & Weekly smoking (\%) \\
\hline $\begin{array}{ll}\text { (1) School no smoking policy } \\
\text { Strong (9 schools, 205 pupils) }\end{array}$ & $9.5(6.1$ to 12.9$)$ & $17.1(14.1$ to 20.0$)$ \\
$\quad$ Medium (39 schools, 993 pupils) & $21.0(17.8$ to 24.2$)$ & $25.5(21.7$ to 29.2$)$ \\
$\quad$ Weak (7 schools, 177 pupils) & $30.1(23.6$ to 36.6$)$ & $34.7(24.7$ to 44.7$)$ \\
$\begin{array}{l}\text { (2) Pupil enforcement } \\
\text { High (29 schools, 730 pupils) }\end{array}$ & $17.7(13.4$ to 22.0$)$ & $22.7(18.3$ to 27.0$)$ \\
$\quad$ Low (26 schools, 645 pupils) & $23.7(20.2$ to 27.2$)$ & $28.6(24.0$ to 33.2$)$ \\
(3) Teacher enforcement & $20.5(14.9$ to 28.2$)$ & $24.0(16.5$ to 31.5$)$ \\
$\quad$ High (39 schools, 997 pupils) & $21.5(14.9$ to 28.2$)$ & $26.2(22.6$ to 29.8$)$ \\
\hline
\end{tabular}

Table 3 Odds ratios (95\% confidence intervals) for pupil level variables from individual level logistic regression models: daily smoking and weekly smoking

\begin{tabular}{|c|c|c|c|c|}
\hline \multirow[b]{2}{*}{ Sex } & \multicolumn{2}{|c|}{ Daily smoking } & \multicolumn{2}{|c|}{ Weekly smoking } \\
\hline & & & & \\
\hline Boy & 1.00 & & 1.00 & \\
\hline Girl & 1.58 & (1.12 to 2.23 ) & 1.74 & (1.24 to 2.43$)$ \\
\hline \multicolumn{5}{|l|}{ Mother smokes? } \\
\hline No & 1.00 & & 1.00 & \\
\hline Yes & 1.65 & (1.20 to 2.27$)$ & 1.40 & (1.00 to 1.96$)$ \\
\hline \multicolumn{5}{|l|}{ Best friend smokes? } \\
\hline No & 1.00 & & 1.00 & \\
\hline Yes, sometimes & 2.36 & $(1.11$ to 5.04$)$ & 5.54 & $(3.45$ to 8.90$)$ \\
\hline Yes, daily & 29.61 & (18.27 to 47.99$)$ & 27.58 & (19.04 to 39.94$)$ \\
\hline \multicolumn{5}{|l|}{ Parents expect too much at school? } \\
\hline No & 1.00 & & 1.00 & \\
\hline Yes & 1.82 & (1.21 to 2.74$)$ & 2.23 & (1.55 to 3.22$)$ \\
\hline Alienation score (OR per unit increase) & 1.41 & (1.17 to 1.70$)$ & 1.39 & (1.19 to 1.62$)$ \\
\hline
\end{tabular}

shows the extent of smoking policy provision at the 55 schools which completed both the pupil and teacher surveys, five of which were independent schools. Of the 53 schools with a policy on pupils' smoking, only one allowed older pupils to smoke in restricted areas, with all other schools prohibiting pupils' smoking completely. Of the 47 schools with a policy on teachers' smoking, 32 allowed teachers to smoke in certain restricted areas, 12 with a written policy and 20 informally. The remaining 15 schools prohibited teachers' smoking on school premises, nine in a written policy and six informally.

At 29 of the 55 schools, restrictions on pupils' smoking were reported to be always enforced in all seven of the areas asked about, giving a maximum pupil enforcement score of 21. Similarly, teachers' smoking restrictions were always enforced in all five areas in 39 out of 54 schools, with one school not providing complete data on this variable. Both of the enforcement scores therefore had highly skewed distributions, and thus were included in all further analyses as binary variables indicating whether or not all restrictions were always enforced.

Questionnaires were completed by 1375 pupils (678 girls, 697 boys) at the 55 schools. No pupils refused to complete the questionnaire: non-response was therefore limited to the small number of sampled pupils in each school that were absent on the day of survey completion. The reported prevalence of daily smoking was $18.2 \%$ among boys and $22.9 \%$ among girls, while weekly smoking prevalence was $21.8 \%$ and $29.2 \%$, respectively. Table 2 shows that daily and weekly smoking were inversely related to the strength of smoking policy provision, with a significant linear trend in both cases $(p<0.001)$. Schools that always enforced pupil policies had significantly lower daily $(p=0.007)$ and weekly $(p=0.013)$ smoking prevalence than schools with weaker enforcement. Enforcement of teachers' policies was not significantly associated with pupils' smoking behaviour ( $p>0.05)$.

There were 27 pupils at the school which did not provide data on enforcement of teachers' smoking restrictions, and a further 102 pupils with a missing response on one or more of the pupil level variables. The remaining 1246 pupils provided complete data for all variables included in multivariable analyses. In each case, the models estimated using all available respondents for each separate analysis and those using the reduced dataset of 1246 pupils were very similar in both the magnitude and significance of estimated relationships. Consequently, for ease of comparison, this paper reports only the models estimated using the reduced dataset. Table 3 displays odds ratios for those pupil level factors found to be significantly associated with daily and weekly smoking. All other pupil factors included in logistic regression analyses were not significantly associated ( $p>0.05)$ with either behaviour and are not included in further reported analyses. Girls, pupils with mothers that smoke, those that report that their parents 
Table 4 Daily smoking: odds ratios (95\% confidence intervals) for school level variables from multilevel logistic regression (models $A-D$ )

\begin{tabular}{|c|c|c|c|c|}
\hline & $A$ & $B$ & $C$ & $D$ \\
\hline Constant & -1.42 & -2.22 & -1.24 & -1.40 \\
\hline \multicolumn{5}{|l|}{ Policy } \\
\hline Strong & & 1.00 & & \\
\hline Average & & $2.30(1.22$ to 4.32$)$ & & \\
\hline Weak & & $3.84(1.76$ to 8.37$)$ & & \\
\hline \multicolumn{5}{|l|}{ Pupil enforcement } \\
\hline High & & & 1.00 & \\
\hline Low & & & $1.41(0.96$ to 2.07$)$ & \\
\hline \multicolumn{5}{|l|}{ Teacher enforcement } \\
\hline High & & & & 1.00 \\
\hline Low & & & & $1.03(0.66$ to 1.59$)$ \\
\hline School level variance(SE) & $0.245(0.101)$ & $0.146(0.082)$ & $0.230(0.099)$ & $0.257(0.104)$ \\
\hline Wald $\chi^{2}(\mathrm{df})$ & & $12.65(2)$ & $3.02(1)$ & $0.01(1)$ \\
\hline $\begin{array}{l}\mathrm{p} \text { Value for contrasts of terms } \\
\text { (added to model) }\end{array}$ & & $\mathrm{p}=0.002(\mathrm{~A})$ & $\mathrm{p}=0.082(\mathrm{~A})$ & $\mathrm{p}=0.913(\mathrm{~A})$ \\
\hline
\end{tabular}

expect too much of them at school, increasing alienation from school, and having a best friend that smokes, were all associated with smoking.

Comparing models $\mathrm{A}$ and $\mathrm{B}$ in table 4 indicates that, for daily smoking, the strength of school smoking policy was significant $(\mathrm{p}=0.002)$, and accounted for approximately $40 \%$ of between school variance. Pupils in schools where pupil smoking policies were not always enforced were at greater risk of being daily smokers (odds ratio 1.41), although this was not significant $(p=0.082)$. Table 5 indicates that all five pupil level variables were significant in all multilevel logistic regression models. Model E included four pupil level variables, all of which were significant but did not reduce the unexplained school level variance. Model $\mathrm{H}$ also included the variable relating to pupils' best friend's smoking status, and this led to a substantial reduction in between school variance. The school policy variable was significant when added to both model E $(p=0.011)$ and model $H$ $(p=0.041)$, although the magnitude of the odds ratios and the degree of significance declined with the addition of pupil level variables. The relationship between enforcement of pupil smoking policies and daily smoking was significant when pupil level variables were controlled for, as shown in models $G$ and J. Teacher policy enforcement was not significant in any case, and is not included in table 5 .

Tables 6 and 7 show that for weekly smoking, the strength of school policy was significant $(p=0.033)$ when added to the null model (A), but did not significantly account for residual between school variance when added to models $\mathrm{E}$ and $\mathrm{H}$, which included pupil level variables. As with daily smoking, best friends' smoking status accounted for a substantial proportion of variation between schools: comparing models $\mathrm{E}$ and $\mathrm{H}$, this variable accounted for $45 \%$ of between school variance. Again, in line with daily smoking, low enforcement of pupils' smoking restrictions was associated with an increased risk of being a weekly smoker, with this relationship being significant in models ( $G$ and $J$ ) that included pupil level variables. Enforcement of teachers' smoking restrictions was not significant in any model.

Table 5 Daily smoking: odds ratios (95\% confidence intervals) for pupil and school level variables from multilevel logistic regression (models E-7)

\begin{tabular}{|c|c|c|c|c|c|c|}
\hline & $E$ & $F$ & $G$ & $H$ & $I$ & $\mathcal{F}$ \\
\hline Constant & -3.26 & -4.00 & -3.03 & -4.52 & -5.18 & -4.32 \\
\hline \multicolumn{7}{|l|}{ Sex } \\
\hline Boy & 1.00 & 1.00 & 1.00 & 1.00 & 1.00 & 1.00 \\
\hline Girl & $1.55(1.13$ to 2.12$)$ & $1.58(1.15$ to 2.16$)$ & $1.58(1.15$ to 2.16$)$ & $1.57(1.08$ to 2.26$)$ & $1.59(1.10$ to 2.30$)$ & $1.57(1.09$ to 2.28$)$ \\
\hline \multicolumn{7}{|l|}{ Mother smokes? } \\
\hline No & 1.00 & 1.00 & 1.00 & 1.00 & 1.00 & 1.00 \\
\hline Yes & 2.51 (1.83 to 3.45$)$ & $2.48(1.81$ to 3.40$)$ & $2.50(1.82$ to 3.43$)$ & 1.65 (1.13 to 2.40$)$ & $1.62(1.11$ to 2.37$)$ & $1.61(1.10$ to 2.36$)$ \\
\hline N/A & $1.04(0.97$ to 1.12$)$ & $1.04(0.97$ to 1.12$)$ & $1.05(0.97$ to 1.13$)$ & $1.01(0.93$ to 1.09$)$ & $1.00(0.92$ to 1.09$)$ & $1.01(0.93$ to 1.10$)$ \\
\hline \multicolumn{7}{|c|}{ Parents expect too much at school? } \\
\hline No & 1.00 & 1.00 & 1.00 & 1.00 & 1.00 & 1.00 \\
\hline Yes & 2.17 (1.60 to 2.94$)$ & 2.17 (1.60 to 2.95$)$ & $2.16(1.59$ to 2.94$)$ & $1.84(1.28$ to 2.63$)$ & 1.84 (1.28 to 2.64$)$ & $1.84(1.28$ to 2.64$)$ \\
\hline \multicolumn{7}{|l|}{ Alienation score (OR per unit } \\
\hline \multicolumn{7}{|l|}{ Best friend smokes? } \\
\hline No & & & & 1.00 & 1.00 & 1.00 \\
\hline Yes, sometimes & & & & $2.37(1.17$ to 4.78$)$ & $2.41(1.20$ to 4.85$)$ & $2.41(1.19$ to 4.85$)$ \\
\hline Yes, daily & & & & $30.0(18.2$ to 49.2$)$ & $29.3(17.9$ to 47.8$)$ & $29.8(18.1$ to 48.9$)$ \\
\hline \multicolumn{7}{|l|}{ Policy } \\
\hline Strong & & 1.00 & & & 1.00 & \\
\hline Average & & $2.19(1.11$ to 4.35$)$ & & & $2.04(1.04$ to 4.00$)$ & \\
\hline Weak & & $3.52(1.55$ to 7.97$)$ & & & $2.77(1.25$ to 6.12$)$ & \\
\hline \multicolumn{7}{|l|}{ Pupil enforcement } \\
\hline High & & & 1.00 & & & 1.00 \\
\hline Low & & & $1.63(1.08$ to 2.45$)$ & & & $1.52(1.03$ to 2.24$)$ \\
\hline School level variance(SE) & $0.295(0.119)$ & $0.202(0.101)$ & $0.251(0.111)$ & $0.077(0.098)$ & $0.036(0.089)$ & $0.066(0.096)$ \\
\hline Wald $\chi^{2}(\mathrm{df})$ & $127.9(5)$ & $9.11(2)$ & $5.40(1)$ & $221.7(2)$ & $6.40(2)$ & $4.49(1)$ \\
\hline \multirow{2}{*}{$\begin{array}{l}\mathrm{p} \text { Value for contrasts of terms } \\
\text { (added to model): }\end{array}$} & & & & & & \\
\hline & $\mathrm{p}<0.0001(\mathrm{~A})$ & $\mathrm{p}=0.011(\mathrm{E})$ & $\mathrm{p}=0.020(\mathrm{E})$ & $\mathrm{p}<0.0001(\mathrm{E})$ & $\mathrm{p}=0.041(\mathrm{H})$ & $\mathrm{p}=0.034(\mathrm{H})$ \\
\hline
\end{tabular}


Table 6 Weekly smoking: odds ratios (95\% confidence intervals) for school level variables from multilevel logistic regression (models $A-D$ )

\begin{tabular}{|c|c|c|c|c|}
\hline & $A$ & $B$ & $C$ & $D$ \\
\hline Constant & -1.14 & -1.63 & -0.99 & -1.25 \\
\hline \multicolumn{5}{|l|}{ Policy } \\
\hline Strong & & 1.00 & & \\
\hline Average & & $1.64(0.93$ to 2.89$)$ & & \\
\hline Weak & & $2.55(1.26$ to 5.15$)$ & & \\
\hline \multicolumn{5}{|l|}{ Pupil enforcement } \\
\hline High & & & 1.00 & \\
\hline Low & & & $1.32(0.92$ to 1.91$)$ & \\
\hline \multicolumn{5}{|l|}{ Teacher enforcement } \\
\hline High & & & & 1.00 \\
\hline Low & & & & $0.86(0.56$ to 1.31$)$ \\
\hline School level variance (SE) & $0.233(0.092)$ & $0.193(0.084)$ & $0.223(0.090)$ & $0.240(0.093)$ \\
\hline Wald $\chi^{2}(\mathrm{df})$ & & $6.80(2)$ & $2.21(1)$ & $0.52(1)$ \\
\hline \multirow{2}{*}{$\begin{array}{l}\mathrm{p} \text { Value for contrasts of terms } \\
\text { (added to model): }\end{array}$} & & & & \\
\hline & & $\mathrm{p}=0.033(\mathrm{~A})$ & $\mathrm{p}=0.138(\mathrm{~A})$ & $\mathrm{p}=0.471(\mathrm{~A})$ \\
\hline
\end{tabular}

\section{Discussion}

It is important to recognise the limitations of the study design. Firstly, as with all cross-sectional studies, evidence of an association should be interpreted carefully before a causal relationship is claimed. In particular, the potential for reverse causality, in which schools where smoking is less of a problem may find it easier to introduce and enforce a strong no smoking policy, cannot be discounted. Secondly, the policy content and enforcement variables used in analysis are crude, unvalidated measures, dependent upon teacher reports. Further research on the relationship between policy and pupil behaviour would be enhanced by a more detailed analysis and finer subdivision of policy content and enforcement, with objective measurement. Thirdly, the pupil data also relied on self reports, both of their smoking behaviour and of the other variables included in analysis. However, unless there was substantial variation across schools in reporting bias, this should not effect the estimated association between policy and smoking prevalence. Finally, the associations found in the multilevel analyses need to be interpreted cautiously, since they may be caused in whole or part by unmeasured differences in the characteristics of schools and their pupils, which may be confounded with smoking policy implementation and enforcement. Moreover, it should be noted that if there are factors omitted from the models that influence both smoking prevalence and the "independent" pupil level variables included in the models, then the latter may not be independent of pupil or school level random effects and may therefore be regarded as endogenous, resulting in inconsistent estimates. Methods to identify the extent of potential endogeneity in non-linear multilevel models are not yet available, ${ }^{24}{ }^{25}$ so the estimates in models that include pupil level variables (tables 5 and 7) should be interpreted cautiously.

In models without pupil level variables, there was significant variation in prevalence between schools for both daily smoking and weekly smoking, which was partially explained by the strength of schools' smoking policy and, to a lesser extent, by the enforcement of pupil smoking policies.

For weekly smoking, the school level variation in smoking prevalence was largely explained by pupil level variables. In particular, best friends' smoking status was a highly significant predictor of each pupils' smoking

Table 7 Weekly smoking: odds ratios (95\% confidence intervals) for pupil and school level variables from multilevel logistic regression (models E-7)

\begin{tabular}{|c|c|c|c|c|c|c|}
\hline & $E$ & $F$ & $G$ & $H$ & $I$ & $\mathcal{F}$ \\
\hline Constant & -3.26 & -4.00 & -3.03 & -4.52 & -5.18 & -4.32 \\
\hline \multicolumn{7}{|l|}{ Sex } \\
\hline Boy & 1.00 & 1.00 & 1.00 & 1.00 & 1.00 & 1.00 \\
\hline Girl & $1.67(1.24$ to 2.25$)$ & $1.69(1.26$ to 2.28$)$ & $1.71(1.27$ to 2.29$)$ & $1.70(1.20$ to 2.40$)$ & $1.70(1.20$ to 2.41$)$ & $1.72(1.22$ to 2.44$)$ \\
\hline \multicolumn{7}{|l|}{ Mother smokes? } \\
\hline No & 1.00 & 1.00 & 1.00 & 1.00 & 1.00 & 1.00 \\
\hline Yes & 2.11 (1.57 to 2.85$)$ & 2.09 (1.55 to 2.82$)$ & $2.10(1.56$ to 2.83$)$ & $1.42(0.99$ to 2.03$)$ & 1.41 (0.98 to 2.02$)$ & $1.40(0.97$ to 2.00$)$ \\
\hline $\mathrm{N} / \mathrm{A}$ & $1.01(0.94$ to 1.09$)$ & 1.01 (0.94 to 1.08$)$ & $1.01(0.95$ to 1.09$)$ & $0.97(0.89$ to 1.05$)$ & $0.97(0.89$ to 1.05$)$ & $0.97(0.90$ to 1.05$)$ \\
\hline \multicolumn{7}{|c|}{ Parents expect too much at school? } \\
\hline No & 1.00 & 1.00 & 1.00 & 1.00 & 1.00 & 1.00 \\
\hline Yes & 2.51 (1.89 to 3.34$)$ & 2.51 (1.89 to 3.35$)$ & 2.51 (1.89 to 3.34$)$ & 2.30 (1.64 to 3.22$)$ & $2.30(1.64$ to 3.23$)$ & $2.30(1.64$ to 3.22$)$ \\
\hline \multicolumn{7}{|l|}{ Alienation score (OR per unit } \\
\hline \multicolumn{7}{|l|}{ Best friend smokes? } \\
\hline No & & & & 1.00 & 1.00 & 1.00 \\
\hline Yes, sometimes & & & & $5.62(3.33$ to 9.49$)$ & $5.70(3.37$ to 9.64$)$ & 5.72 (3.38 to 9.67$)$ \\
\hline Yes, daily & & & & $28.6(18.3$ to 44.6$)$ & $28.4(18.2$ to 44.3$)$ & $28.5(18.2$ to 44.4$)$ \\
\hline \multicolumn{7}{|l|}{ Policy } \\
\hline Strong & & 1.00 & & & 1.00 & \\
\hline Average & & $1.56(0.84$ to 2.90$)$ & & & $1.34(0.71$ to 2.52$)$ & \\
\hline Weak & & $2.34(1.08$ to 5.08$)$ & & & $1.79(0.81$ to 3.99$)$ & \\
\hline \multicolumn{7}{|l|}{ Pupil enforcement } \\
\hline High & & & 1.00 & & & 1.00 \\
\hline Low & & & 1.53 (1.03 to 2.26$)$ & & & $1.49(1.01$ to 2.20$)$ \\
\hline School level variance (SE) & $0.277(0.108)$ & $0.249(0.102)$ & $0.245(0.102)$ & $0.153(0.103)$ & $0.159(0.105)$ & $0.132(0.099)$ \\
\hline Wald $\chi^{2}(\mathrm{df})$ & $138.1(5)$ & $4.60(2)$ & $4.47(1)$ & $230.1(2)$ & $2.07(2)$ & $3.95(1)$ \\
\hline \multirow{2}{*}{$\begin{array}{l}\mathrm{p} \text { Value for contrasts of terms } \\
\text { (added to model) }\end{array}$} & & & & & & \\
\hline & $\mathrm{p}<0.0001(\mathrm{~A})$ & $\mathrm{p}=0.100(\mathrm{E})$ & $\mathrm{p}=0.034(\mathrm{E})$ & $\mathrm{p}<0.0001(\mathrm{E})$ & $\mathrm{p}=0.356(\mathrm{H})$ & $\mathrm{p}=0.047(\mathrm{H})$ \\
\hline
\end{tabular}


behaviour, and accounted for about $45 \%$ of interschool variation in weekly smoking. This variable accounted for an even greater proportion $(74 \%)$ of interschool variation in daily smoking. Nevertheless, strength of school smoking policy was significant in all models of daily smoking prevalence, although the magnitude of the association was diminished when pupil level variables were included. This suggests that there was some confounding between schools' smoking policy and the characteristics of schools' pupils, but that the association between policy and daily smoking remained after adjusting for this. The apparently weaker association between school smoking policy and weekly smoking may reflect the fact that pupils who smoke socially at weekends, but not during the week, will be doing so in contexts outside the influence of school smoking policies. The variable influence of school policy on pupils' smoking behaviour is in line with other research which found that policy was related to lower amounts of adolescent smoking, but less strongly related to smoking prevalence. ${ }^{13}$

Prevalence of both daily and weekly smoking was lower in schools where pupil smoking restrictions were always enforced in all areas. The magnitude of this association was consistent across all multilevel analyses, although it was not always statistically significant. The enforcement of teacher related smoking restrictions was not significant in any analysis. Schools with weak policies, but nevertheless claiming strong enforcement of these policies, will attenuate the apparent significance of this factor in the reported analyses. While work undertaken elsewhere has also highlighted the importance of strong policy enforcement in schools, ${ }^{15}$ further analysis of how enforcement interacts with policy content is warranted. However, this was not possible in the present study, because of the limited number of schools.

Smoking policies have the potential to be developed, implemented and monitored in schools, requiring minimal funding and staff commitment. Detailed advice is available to schools to assist in this process. ${ }^{26}$ Such an approach is likely to be a realistic option for schools and sustainable in the longer term. This is in direct contrast to complex interventions which, although successful in the short term, are unlikely to be sustained given competing demands on teachers' time and pressure on budgets. ${ }^{27}$ While this may be the case, the development of smoking policy still requires careful consideration. Research has indicated that there are numerous barriers to taking action, notably in relation to policies addressing teachers' smoking. ${ }^{28}$

Progress is most likely if the introduction of policy forms one component of an integrated, comprehensive approach to smoking prevention in schools, where policy can reinforce the taught curriculum and specific health education initiatives. This focus on the school environment is consistent with the health promoting school approach.

\section{What this paper adds}

Many schools have policies regarding smoking by pupils, teachers and others on the school premises, but the content and enforcement of these policies are variable. Evidence on the effectiveness of such policies is mixed, and no published studies have been conducted in the UK.

In line with the weight of evidence elsewhere, this study demonstrates an association between policy strength, policy enforcement, and pupils' smoking behaviour in the UK. The findings support the wider introduction of strongly enforced comprehensive smoking policies in secondary schools.

\section{CONCLUSIONS}

While this study alone cannot provide evidence that school smoking policies can impact upon pupils' smoking prevalence, it does demonstrate an association between policy strength, policy enforcement, and pupils' smoking behaviour. Further research is necessary to identify the ideal composition of school smoking policies and effective means for their introduction. The impact of school smoking policies on pupils' smoking prevalence would best be identified through a cluster randomised trial. Until such a study has been undertaken, the true impact of school smoking policy on pupils' smoking behaviour will be impossible to quantify, but the findings of this study would support the wider introduction of comprehensive school smoking policies in secondary schools in the UK.

The views expressed in this paper are those of the authors and not necessarily those of the National Assembly for Wales. We thank HBSC colleagues involved in developing this study: Wolfgang Dür (Austria); Danielle Piette (French speaking Belgium); Bjørn Holstein and Lis Jensen (Denmark); Lasse Kannas and Jorma Tynjälä (Finland); Bettina Schmidt (Germany); Bente Wold (Norway); Candace Currie and Dawn Griesbach (Scotland).

Competing interests: None.

Funding: National Assembly for Wales. CR has also received support from the European Commission, through Concerted Action Contract BMH4-CT98-3721 (DG 12-SSMI)

1 Roberts C, Kingdon A, Frith C, et al. Young people in Wales: lifestyle changes 1986-1996. Health Promotion Wales Technical Report 24. Cardiff: Health Promotion Wales, 1997.

2 Nic Gabhainn S, François Y. Substance use. In: Currie C, Hurrelmann K, Settertobulte W, et al, eds. Health and health behaviour among young people. Health behaviour in health behaviour among young people. Health behaviour in school-aged children: a WHO cross national study (HBSC) international report. Copenhagen: World

3 Secretary of State for Health, Secretary of State for Scotland, Secretary of State for Wales and Secretary of Scotland, Secretary of State for Wales and Secretary of
State for Northern Ireland. Smoking kills. A white paper on tobacco. London: Stationery Office, 1998.

4 Welsh Office. Better health better Wales, a consultation paper. Cm 3922. Cardiff: Welsh Office, 1998.

5 Tyas SL, Pederson LL. Psychosocial factors related to adolescent smoking: a critical review of the literature. Tobacco Control 1998;7:409-20.

6 NHS Centre for Reviews and Dissemination, University of York. Effective health care bulletin. Preventing the uptake of smoking in young people. October 1999, volume 5, number 5.

7 Reid DJ, McNeill AD, Glynn TJ. Reducing the prevalence of smoking in youth in western countries: an international review. Tobacco Control 1995;4:266-77.

8 Anderson P. The smoking gun. In: European Commission/ International Union for Health Promotion and Education. The evidence of health promotion effectiveness. Shaping public The evidence of health promotion effectiveness. Shaping public health in a new Europe. B

9 Stead M, Hastings G, Tudor-Smith C. Preventing adolescent smoking: a review of the options. Health Educ $\mathcal{F} 1996$; 55:31-54. 
10 Lantz PM, Jacobson PD, Warner KE, et al. Investing in youth tobacco control: a review of smoking prevention and youth tobacco control: a review of smoking preve

11 Bowker S, Tudor-Smith C. The European network of health promoting schools: development and evaluation in Wales. Health Educ F 1996;55:457-64.

12 Stears D. Evaluating the implementation of the European network of health promoting schools in six European countries. Health Educ 1998;5:173-81.

13 Pentz MA, Brannon BR, Charlin VL, et al. The Power of Policy: The relationship of smoking policy to adolescent smoking. Am f Public Health 1989;79:857-62.

14 Maes L, Lievens J. Adolescent smoking behaviour and the school. A multilevel analysis. In: Tudor-Smith C, ed. Working together for better health. Tackling tobacco. Cardiff: Health Promotion Wales, 1999:113-28.

15 Wakefield MA, Chaloupka FJ, Kaufman NJ, et al. Effect of restrictions on smoking at home, at school, and in public
places on teenage smoking: cross sectional study. BMF places on teenage

16 Clarke V, White V, Hill D, et al. School structural and policy variables associated with student smoking. Tobacco Control variables associated

17 Currie C, ed. Health behaviour in school-aged children, a WHO cross-national study. Research protocol for the 1997/98 survey. Research Unit in Health \& Behavioural Change. Edinburgh: University of Edinburgh, 1998.

18 StataCorp. Stata statistical software: release 6.0. College Station, Texas: Stata Corporation, 1999.

19 Smith C, Roberts C, Moore L. Parents and adolescent smoking. F Inst Health Educ 1995;33:104-9.
20 Nutbeam D, Smith C, Moore L, et al. Warning! Schools can damage your health: alienation from school and its impact on health behaviour. $\mathcal{f}$ Paediatr Child Health 1993; 29:(suppl 1):S25-30.

21 Mullan E, Currie C. Socioeconomic inequalities in adolescent health. In Currie C, Hurrelmann K, Settertobulte W, et al, eds. Health and health behaviour among young people. Health behaviour in school-aged children: a WHO cross national study (HBSC) international report. Copenhagen: World Health Organisation Regional Office for Europe, 2000.

22 Goldstein H, Rasbash J, Plewis I, et al. A user's guide to MLwiN. London: Institute of Education, 1998.

23 Goldstein H, Rasbash J. Improved approximations for multilevel models with binary responses. $7 R$ Statist Soc $A$ 1996;159:505-13.

24 Spencer NH, Fielding A. A comparison of modelling strategies for value-added analyses of educational data. Computational Statistics (in press)

25 Rice N, Jones A, Goldstein H. Multilevel models where the random effects are correlated with the fixed predictors: a conditioned iterative generalised least squares estimator (CIGLS). Multilevel Modelling Newsletter 1998;10:7-11.

26 West R, Foulds J. Smoke-free schools: seven steps to success. London: Health Education Authority, 1999.

27 Reid D. Failure of an intervention to stop teenagers smoking. BMF 1999;319:934-35.

28 Hartland J, Tudor-Smith C, Bowker S. Smoke-free policies in schools: a qualitative investigation of the benefits and barriers. Health Educ F 1998;57:51-9.

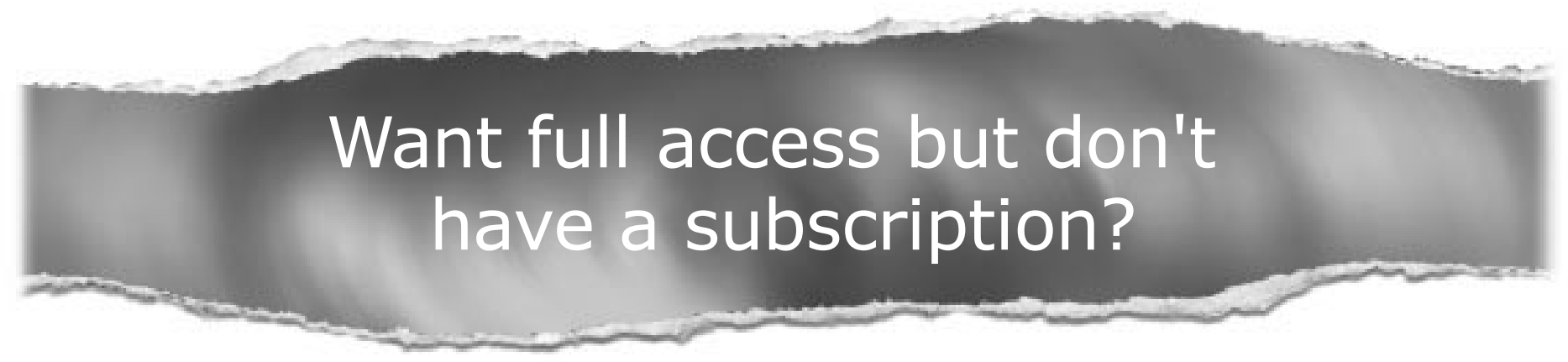

\section{Pay per access}

For just US $\$ 25$ you can have instant access to the whole website for 30 days. During this time you will be able to access the full text for all issues (including supplements) available. You will also be able to download and print any relevant pdf files for personal use, and take advantage of all the special features Tobacco Control online has to offer.

\section{www.tobaccocontrol.com}

